
.

\title{
GENETICS IN ENDOCRINOLOGY \\ Genetic variation in deiodinases: a systematic review of potential clinical effects in humans
}

\author{
Herman Verloop ${ }^{1}$, Olaf M Dekkers ${ }^{2}$, Robin P Peeters ${ }^{4}$, Jan W Schoones ${ }^{5}$ and \\ Johannes W A Smit ${ }^{1,3}$ \\ Departments of ${ }^{1}$ Endocrinology and ${ }^{2}$ Clinical Epidemiology, Leiden University Medical Center, Leiden, \\ The Netherlands, ${ }^{3}$ Department of General Internal Medicine, Radboud University Medical Center, PO Box 9101, \\ 6500 HB Nijmegen, The Netherlands, "${ }^{4}$ Department of Endocrinology, Erasmus University Medical Center, \\ Rotterdam, The Netherlands and ${ }^{5}$ Walaeus Medical Library, Leiden University Medical Center, Leiden, \\ The Netherlands
}

Correspondence should be addressed to J W A Smit Email

J.Smit@aig.umcn.nl

\section{Abstract}

lodothyronine deiodinases represent a family of selenoproteins involved in peripheral and local homeostasis of thyroid hormone action. Deiodinases are expressed in multiple organs and thyroid hormone affects numerous biological systems, thus genetic variation in deiodinases may affect multiple clinical endpoints. Interest in clinical effects of genetic variation in deiodinases has clearly increased. We aimed to provide an overview for the role of deiodinase polymorphisms in human physiology and morbidity. In this systematic review, studies evaluating the relationship between deiodinase polymorphisms and clinical parameters in humans were eligible. No restrictions on publication date were imposed. The following databases were searched up to August 2013: Pubmed, EMBASE (OVID-version), Web of Science, COCHRANE Library, CINAHL (EbscoHOST-version), Academic Search Premier (EbscoHOST-version), and ScienceDirect. Deiodinase physiology at molecular and tissue level is described, and finally the role of these polymorphisms in pathophysiological conditions is reviewed.

Deiodinase type 1 (D1) polymorphisms particularly show moderate-to-strong relationships with thyroid hormone parameters, IGF1 production, and risk for depression. D2 variants correlate with thyroid hormone levels, insulin resistance, bipolar mood disorder, psychological well-being, mental retardation, hypertension, and risk for osteoarthritis.

D3 polymorphisms showed no relationship with inter-individual variation in serum thyroid hormone parameters.

One D3 polymorphism was associated with risk for osteoarthritis. Genetic deiodinase profiles only explain a small proportion of inter-individual variations in serum thyroid hormone levels. Evidence suggests a role of genetic deiodinase variants in certain pathophysiological conditions. The value for determination of deiodinase polymorphism in clinical practice needs further investigation.

\section{Introduction}

The relationship between variation in thyroid hormone pathway genes and their effects on clinical phenotypes represents a relatively new field of research. In the last few years, the influence of deiodinase polymorphisms on various thyroid hormone-related endpoints is considered a topic of particular interest. Iodothyronine deiodinases represent a family of selenoproteins involved in local and peripheral homeostasis of thyroid hormones.
Three deiodinases have been described. Deiodinase type 1 (D1) and D2 play a major role in conversion of thyroxine $\left(\mathrm{T}_{4}\right)$ to biologically active tri-iodothyronine $\left(\mathrm{T}_{3}\right)$ and in clearance of reverse $\mathrm{T}_{3}\left(\mathrm{rT}_{3}\right)$ (1). Although both deiodinases are determinants of peripheral thyroid hormone levels, D2 is particularly renowned for its role in local $\mathrm{T}_{3}$ production $(2,3)$. D3 is the main $\mathrm{T}_{3}$-inactivating enzyme, regulating the conversion of $T_{3}$ to $T_{2}$ and $T_{4}$ to $\mathrm{rT}_{3}(1)$.
(ㄷ) 2014 European Society of Endocrinology Printed in Great Britain
Published by Bioscientifica Ltd. 
Deiodinases have a tissue-specific expression pattern $(1,2)$. D1 protein is mainly expressed in liver, kidney, thyroid, and euthyroid pituitary (1). D2 protein is detected in the CNS, pituitary, skeletal muscle, thyroid, heart, bone, and brown adipose tissue (2). D3 is located in the CNS and placenta in adult life and is predominantly expressed in many tissues during fetal life $(1,2)$.

Bearing in mind that deiodinases affect thyroid hormone regulation in a wide range of tissues, genetic variation in these seleno-enzymes might affect various organ systems. In the last few years, several deiodinase polymorphisms with putative impact on functional enzyme activity have been detected $(4,5,6,7,8)$. In this systematic review, available evidence for the impact of deiodinase polymorphisms on various clinical domains in humans is summarized. Furthermore, we aimed to evaluate whether determination of a genetic deiodinase profile may be a valuable new endocrinological tool in future clinical practice.

\section{Methods}

\section{Eligibility criteria and search strategy}

Studies evaluating the relationship between deiodinase polymorphisms and clinical parameters in human populations were eligible. No restrictions on publication date were imposed. The search strategy was composed in cooperation with a trained librarian. The following databases were searched up to 13 August 2013: Pubmed, EMBASE (OVID-version), Web of Science, COCHRANE Library, CINAHL (EbscoHOST-version), Academic Search Premier (EbscoHOST-version), and ScienceDirect. For two concepts (deiodinase and polymorphisms), relevant keyword variations were used, not only variations in the controlled vocabularies of the various databases, but also free text word variations. This search strategy was optimized for all consulted databases. Reference lists of studies eligible for inclusion were hand-searched and checked for additional relevant articles.

\section{Effect of deiodinase polymorphisms on mRNA and protein synthesis}

To provide a better understanding of the putative effects of deiodinase polymorphisms on clinical parameters in our systematic review of literature, we first aimed to describe available evidence on the impact of deiodinase variants on the mRNA and deiodinase protein level.
D1 polymorphisms - The human D1 gene $(2-2.1 \mathrm{~kb})$ is located on chromosome 1p32-p33 and comprises four exons (9). Three polymorphisms, D1-rs2235544; D1-rs11206244 (DI-C785T); and D1-rs12095080 (DI-A1814G), are highlighted as potential candidates associated with physiological and pathological processes in humans. The D1-rs2235544 polymorphism is located in intron 3 of the D1 gene (10); D1-rs11206244 and D1-rs12095080 are located in the $3^{\prime}$-UTR of the mRNA (7). An in vitro study revealed no clear effect of the C785T or A1814G variant on mRNA level, mRNA decay rate, or D1 activity (11). A large genome-wide study revealed that within $100 \mathrm{~kb}$ of the D1 gene no association between genetic variants and altered D1 expression levels in lymphocytes could be found, thereby questioning the effect of genetic variants in the D1 gene $(10,12)$. As functionality of D1 polymorphisms has not yet been shown, more research is warranted to determine its exact influence on D1 activity at gene and protein level.

D2 polymorphisms - The human $D 2$ gene $(15 \mathrm{~kb})$ maps to chromosome 14q24.2-q24.3 and consists of three exons (13). The D2-rs12885300 (D2-ORF a $_{\mathrm{a}}$-Glu3Asp) and D2-rs225014 (D2-Thr92Ala) polymorphisms in exons 1 and 2 , respectively, have been frequently evaluated in clinical research.

The D2-ORF ${ }_{\mathrm{a}}$-Glu3Asp polymorphism is located in the short open reading frame within the $5^{\prime}$-UTR of the D2 gene (6). An in vitro study by Coppotelli et al. (8) showed that the minor allele variant of D2-ORF - -Glu3Asp polymorphism was associated with an increased gene transcription and ultimately increased D2 activity. In a second in vitro study by Gereben et al. (14), however, the D2-ORF $\mathrm{a}_{\mathrm{a}}$ Glu3Asp polymorphism did not affect the expression of a D2 sequence reporter mRNA but did decrease D2 activity by about fivefold. Hoftijzer et al. (15) proposed that the discrepancies between the two studies may be related to the reporter genes used (e.g. a selenoprotein and a non-selenoprotein). From the study of Gereben et al., it may be concluded that the D2 activity/D2 mRNA ratio is low, suggesting a posttranslational regulation (15).

The Thr92Ala polymorphism is characterized by the first amino acid substitution located in the instability loop of D2, a site of importance for D2 turnover rate (16). In vitro studies were inconsistent on the functionality of the Thr92Ala variant. D2 enzyme velocity was decreased in skeletal muscle and thyroid tissue samples of type 2 diabetes mellitus (DM2) patients who were homozygous for the Thr92Ala variant (5). In contrast, in vitro analysis in 
cells transfected with WT or variant D2 revealed no significant differences in D2 activity between the genotypes (17). This discrepancy might be explained by linkage of D2-Thr92Ala to a functional variant elsewhere in the genome. Table 1 provides an overview detailing the prevalence of frequently investigated D1 and D2 polymorphisms in different populations. See supplementary table 1 (see section on supplementary data given at the end of this article) for an overview of studies and their primary clinical endpoints

D3 polymorphisms - The human D3 gene maps to chromosome 14q32.2, consists of one exon, and is located in a human imprinted domain (18). To our knowledge, the effect of DIO3 variants on functional characterization of the DIO3 protein has not been studied. The effect of D3 variants on D3 activity might be hampered by the epigenetic process of genetic imprinting. Effects of D3 polymorphisms on thyroid hormone homeostasis depend on the parental origin of the variant allele (7).

\section{Organ and tissue-specific effects of deiodinase polymorphisms}

\section{Pituitary-thyroid axis}

D1 polymorphisms - The impact of the D1-C785T polymorphism on basal serum thyroid hormone parameters has been evaluated in several studies. The D1-785T variant was related to higher serum concentrations of $\mathrm{fT}_{4}(10,11,19,20,21,22,23)$ and $\mathrm{rT}_{3}(11,17$, $19,20)$, lower serum concentrations of $\mathrm{T}_{3}$ or $\mathrm{fT}_{3}(10,20$, $23,24)$, and lower $\mathrm{T}_{3} / \mathrm{rT}_{3}$ or $\mathrm{fT}_{3} / \mathrm{fT}_{4}$ ratios $(10,11,17,19$, $20)$, overall pointing toward a decreased conversion of $\mathrm{T}_{4}$ to $\mathrm{T}_{3}$ by diminished $\mathrm{D} 1$ protein expression or activity. More specifically, the D1-C785T polymorphism was linked to higher $\mathrm{rT}_{3}$ serum levels and a lower $\mathrm{T}_{3} / \mathrm{rT}_{3}$ ratio in healthy young mixed cohorts (mean age, 36.7 and 46.2 years) (11, 17), healthy young men (mean age, 25-45 years) (19), and a cohort of elderly subjects (mean age, 72.2 years) (20). Although in elderly populations (mean age, $>70$ years) the D1-785T variant was associated with lower $\mathrm{T}_{3}$ serum levels $(20,24)$, this could not be replicated in healthy young mixed cohorts (mean age, 36.7 and 46.2 years $)(11,17)$. D1 may have larger contribution to serum $\mathrm{T}_{3}$ production in older age. In young subjects, a decreased $\mathrm{T}_{3}$ production may be masked by the production of serum $\mathrm{T}_{3}$ by $\mathrm{D} 2$ in skeletal muscle. Throughout adult life, skeletal muscle size and strength gradually decline, resulting in a decrease in D2-expressing skeletal muscle (7). Therefore, potential effects of D1 polymorphisms on serum $\mathrm{T}_{3}$ production might only result in changes in serum $\mathrm{T}_{3}$ levels in elderly subjects. Research by Panicker et al. (10) showed higher $\mathrm{fT}_{4}$ levels, lower $\mathrm{fT}_{3}$ levels, and a lower $\mathrm{fT}_{4} / \mathrm{fT}_{3}$ ratio in carriers of the D1-785T variant in a large population $(n=552)$ of patients on thyroid hormone replacement and this tendency was confirmed in patients not on thyroid hormone replacement therapy. Concordantly, Philibert et al. (22) reported an association between higher $\mathrm{fT}_{4}$ levels and the D1-785T allele in large cohorts including White and Afro-American subjects. Medici et al. (21) performed a large-scale association analysis in four large independent cohorts $(n=3777)$ and detected a robust association between the D1-C785 $\mathrm{T}$ polymorphism and serum $\mathrm{fT}_{4}$, with higher $\mathrm{fT}_{4}$ in carriers of the D1-785T variant allele. In a small study including preeclamptic women, the variant was associated with higher $\mathrm{T}_{4}$ and lower $\mathrm{fT}_{3}$ levels (23). Collectively, these findings support the hypothesis of a decreased D1 activity in carriers of the D1-785T variant, inducing a lower conversion of $\mathrm{T}_{4}$ to $\mathrm{T}_{3}$ and lower $\mathrm{rT}_{3}$ clearance.

The minor allele variant (T-allele) of the D1-rs2235544 polymorphism was associated with variation in serum iodothyronine levels, evidenced by significantly lower serum $\mathrm{fT}_{4}$ levels and higher $\mathrm{fT}_{3} / \mathrm{fT}_{4}$ ratio in large euthyroid as well as non-euthyroid populations $(10,19,21,22,25)$. Recent evidence supports a strong correlation between $\mathrm{fT}_{4}$ levels and D1-rs2235544 polymorphism in a large meta-analysis ( $n>40000$ subjects; $P=7.87 \times 10^{-32}$ ) (26). These findings might point toward an increased D1 activity of the T-allele.

The D1-A1814G polymorphism was associated with a higher $\mathrm{T}_{3} / \mathrm{rT}_{3}$ ratio in two independent cohorts of elderly and young subjects $(17,20)$, suggesting that this genetic variant may confer a decreased functional activity to the D1 protein. On the contrary, the genetic variant had no significant impact on thyroid hormone levels or thyroid hormone ratios in another large healthy population of relatively young age (mean age, 36 years) (11).

Although the impact of genetic profile on interindividual variation in serum thyroid hormone levels is assumed to be large, it is important to consider that the solitary effect of D1 polymorphisms on thyroid function is assumed to be relatively small (variation explained by D1-rs2235544 and DI-C785T for serum $\mathrm{fT}_{4}, 2$ and $0.87 \%$ respectively) $(10,11)$.

D2 polymorphisms - The lack of association between the D2-Thr92Ala polymorphism and serum iodothyronine or thyroid-stimulating hormone (TSH) levels has been 
Table 1 Overview detailing the prevalence of frequently investigated D1 and D2 polymorphisms in different populations.

\begin{tabular}{|c|c|c|c|}
\hline Study & D1 and D2 polymorphisms & $\boldsymbol{n}$ (number of patients) & Origin of population \\
\hline \multicolumn{4}{|c|}{ D1-C785T polymorphism (T-allele frequency) } \\
\hline (44) & 0.42 & 64 & Patients diagnosed with major depression \\
\hline (20) & $0.36^{\mathrm{a}}$ & 995 & Elderly Caucasians \\
\hline (15) & $0.36^{\mathrm{a}}$ & 148 & Patients treated for DTC \\
\hline (10) & $0.34^{\mathrm{a}}$ & 546 & $\begin{array}{l}\text { Patients on thyroid hormone replacement } \\
\text { therapy }\end{array}$ \\
\hline (17) & 0.34 & 156 & Healthy European blood donors \\
\hline (24) & 0.34 & 349 & Healthy elderly men \\
\hline (23) & $0.24(\mathrm{C}) / 0.37(\mathrm{PW})$ & 100 & $\begin{array}{l}\text { Pregnant women: healthy controls }(n=50) \\
\text { and subjects with preeclampsia }(n=50)\end{array}$ \\
\hline (11) & 0.34 & 1192 & Healthy Danish twins \\
\hline \multicolumn{4}{|c|}{ D1-A1814G polymorphism (G-allele frequency) } \\
\hline (44) & 0.09 & 64 & Patients diagnosed with major depression \\
\hline (20) & $0.10^{\mathrm{b}}$ & 995 & Elderly Caucasians \\
\hline$(15)$ & $0.09^{b}$ & 147 & Patients treated for DTC \\
\hline (17) & 0.10 & 156 & Healthy European blood donors \\
\hline (24) & 0.11 & 349 & Healthy elderly men \\
\hline$(11)$ & 0.11 & 1076 & Healthy Danish twins \\
\hline \multicolumn{4}{|c|}{ D2-Thr92Ala polymorphism $\left({ }^{92} \mathrm{Ala}\right.$ allele frequency) } \\
\hline (27) & 0.40 & 141 & Patients with PAH \\
\hline (37) & 0.24 (C)/0.32 (Graves) & 315 & $\begin{array}{l}\text { Russian population: healthy blood donors } \\
(n=135) \text { and patients with Graves' } \\
\text { disease }(n=180)\end{array}$ \\
\hline (45) & $0.31^{a}$ & 93 & Patients diagnosed with major depression \\
\hline (34) & 0.41 & 83 & Healthy volunteers \\
\hline (5) & 0.41 & 183 & Patients with DM2 \\
\hline (67) & 0.41 & 315 & Patients with DM2 \\
\hline (44) & 0.41 & 64 & Patients diagnosed with major depression \\
\hline (20) & $0.37^{\mathrm{a}}$ & 995 & Elderly Caucasians \\
\hline (58) & $0.38(\mathrm{C}) / 0.38(\mathrm{DM} 2)$ & 1573 & $\begin{array}{l}\text { Patients with DM2 }(n=1057) \text { and controls } \\
\text { without DM2 }(n=516)\end{array}$ \\
\hline (59) & 0.390 & 721 & Patients with DM2 \\
\hline$(60)$ & 0.36 & 590 & Nondiabetic Caucasians \\
\hline (61) & 0.36 & 5843 & Danish white subjects \\
\hline (33) & $0.25^{\mathrm{a}}$ & 145 & Patients with Graves' disease \\
\hline (30) & $0.36(\mathrm{C}) / 0.38(\mathrm{TA})$ & 216 & $\begin{array}{l}\text { Healthy controls ( } n=106) \text { and subjects with } \\
\text { thyroid autoimmunity }(n=110)\end{array}$ \\
\hline (31) & 0.320 (NTP)/0.390 (HTP) & 372 & $\begin{array}{l}\text { Normotensive }(n=68) \text { and hypertensive } \\
(n=304) \text { euthyroid subjects }\end{array}$ \\
\hline (76) & $0.38(\mathrm{C}) / 0.35$ (MR) & $543^{k}$ & $\begin{array}{l}\text { Controls }(n=331) \text { and mentally retarded } \\
(n=96) \text { derived from iodine-deficient } \\
\text { areas in China }\end{array}$ \\
\hline (46) & $0.41(C) / 0.53$ (BPAD) & 563 & $\begin{array}{l}\text { Chinese Han population: } \mathrm{C}(n=284) \text { and } \\
\text { patients with BPAD }(n=279)\end{array}$ \\
\hline (28) & $0.40(\mathrm{DTC}) / 0.40(\mathrm{HT})$ & 295 & $\begin{array}{l}\text { Patients treated for DTC }(n=154) \text { and } \\
\text { patients with HT }(n=141)\end{array}$ \\
\hline$(15)$ & $0.40^{\mathrm{a}}$ & 148 & Patients treated for DTC \\
\hline (75) & $\begin{array}{l}0.40(\mathrm{C}) / 0.31(\mathrm{SS}) / 0.26(\mathrm{ALI})^{\mathrm{c}} \text { and } \\
0.44(\mathrm{C}) / 0.44(\mathrm{SS}) / 0.46(\mathrm{ALI})^{\mathrm{d}}\end{array}$ & $405^{c} / 302^{d}$ & $\begin{array}{l}\text { European Americans: C }(n=188) ; \text { SS } \\
\quad(n=139) ; \mathrm{ALI}(n=78) \text { and African- } \\
\text { Americans: } \mathrm{C}(n=187) ; \text { SS }(n=74) ; \\
\text { ALI }(n=41)\end{array}$ \\
\hline$(63)$ & 0.37 & 1633 & White subjects of mixed European ancestry \\
\hline (4) & 0.35 & 972 & Nondiabetic Caucasians \\
\hline (32) & 0.30 & 1268 & Old order Amish population \\
\hline (39) & 0.35 & 360 & $\begin{array}{l}\text { Caucasian subjects with symptomatic } \\
\text { osteoarthritis }\end{array}$ \\
\hline (64) & 0.82 & $300^{e}$ & Pima Indians \\
\hline (43) & $0.36\left(T_{4}\right)^{a, f} / 0.38\left(T_{4} / T_{3}\right)^{a, g}$ & 552 & $\begin{array}{l}\text { Patients on thyroid hormone replacement } \\
\text { therapy }\left(\mathrm{T}_{4} \text { only }(n=282) \text { and } \mathrm{T}_{4} / \mathrm{T}_{3}\right. \\
\text { combined }(n=270))\end{array}$ \\
\hline (17) & 0.39 & 156 & Healthy European blood donors \\
\hline
\end{tabular}


Table 1 Continued

\begin{tabular}{|c|c|c|c|}
\hline Study & D1 and D2 polymorphisms & $\boldsymbol{n}$ (number of patients) & Origin of population \\
\hline (29) & 0.39 & 191 & Patients treated for DTC \\
\hline (69) & $0.37^{\mathrm{h}} / 0.38^{\mathrm{i}}$ & 2441 & $\begin{array}{l}\text { Two cohorts of elderly Caucasians: } \\
n=1444 / n=997\end{array}$ \\
\hline$(82)$ & $0.44(\mathrm{C}) / 0.46(\mathrm{KBD})$ & 473 & $\begin{array}{l}\text { Chinese Han population: Controls }(n=161) \\
\text { and patients with KBD }(n=312)\end{array}$ \\
\hline (77) & 0.561 & 1461 & Chinese Han population \\
\hline \multicolumn{4}{|c|}{ D2-ORF $_{a}$-Gly3Asp polymorphism ( ${ }^{3}$ Asp allele frequency) } \\
\hline (27) & 0.32 & 141 & Patients with PAH \\
\hline (44) & 0.30 & 64 & Patients diagnosed with major depression \\
\hline (20) & $0.35^{\mathrm{a}}$ & 995 & Elderly Caucasians \\
\hline (46) & $0.26(C) / 0.19$ (BPAD) & 563 & $\begin{array}{l}\text { Chinese Han population: } \operatorname{PHC}(n=284) \text { and } \\
\text { patients with BPAD }(n=279)\end{array}$ \\
\hline (15) & $0.31^{\mathrm{a}}$ & 147 & Patients treated for DTC \\
\hline (75) & $\begin{array}{l}0.36(\mathrm{C}) / 0.37(\mathrm{SS}) / 0.41(\mathrm{ALI})^{\mathrm{c}} \text { and } \\
0.06(\mathrm{C}) / 0.10(\mathrm{SS}) / 0.12(\mathrm{ALI})^{\mathrm{d}}\end{array}$ & $405^{c} / 302^{d}$ & $\begin{array}{l}\text { European Americans: C }(n=188) ; \text { SS }(n=139) ; \\
\text { ALI }(n=78) \text { and African-Americans: } \\
\text { C }(n=187) ; \text { SS }(n=74) ; \text { ALI }(n=41)\end{array}$ \\
\hline (39) & $0.34^{j}$ & 360 & $\begin{array}{l}\text { Caucasian subjects with symptomatic } \\
\text { osteoarthritis }\end{array}$ \\
\hline (6) & 0.34 (HBD)/0.34 (HEM) & 505 & $\begin{array}{l}\text { Healthy European blood donors }(n=156) \\
\text { and healthy elderly men }(n=349)\end{array}$ \\
\hline (69) & $0.36^{\mathrm{h}} / 0.35^{\mathrm{i}}$ & 2441 & $\begin{array}{l}\text { Two cohorts of elderly Caucasians: } \\
n=1444 / n=997\end{array}$ \\
\hline
\end{tabular}

C, controls; PAH, primary autoimmune hypothyroidism; HTP, hypertensive patients; NTP, normotensive patients; BPAD, bipolar affective disorder; PHC, psychiatrically healthy controls; DM2, diabetes mellitus type 2; SS, patients with severe sepsis; ALI, patients with severe sepsis and acute lung injury; HBD, healthy blood donors; HEM, healthy elderly men; KBD, Kashin-Beck disease; DTC, differentiated thyroid carcinoma; PW, preeclamptic women.

${ }^{a}$ Extracted from reported genotype frequencies.

b Including studies in which allele frequencies of the polymorphism were reported or could be extracted.

'Determined in European Americans.

dDetermined in African-Americans.

Including diabetic subjects $(n=150)$ and nondiabetic subjects $(n=150)$.

${ }^{f}$ Allele frequency determined in a study including patients on thyroid hormone replacement, randomized to $\mathrm{T}_{4}$ therapy only group.

${ }^{g}$ Allele frequency determined in a study including patients on thyroid hormone replacement, randomized to combined $\mathrm{T}_{4} / \mathrm{T}_{3}$ therapy.

${ }^{\mathrm{h}}$ The Rotterdam Study is a population-based, prospective cohort study on chronic and disabling diseases in the elderly.

iThe Rotterdam Scan Study is an ongoing prospective population-based cohort study designed to investigate causes and consequences of age-related changes in brain shown up on magnetic resonance imaging.

${ }^{\mathrm{j}}$ In siblings affected by osteoarthritis sharing 0 alleles identical by descent (see article for more details).

${ }^{k}$ Including borderline mentally retarded patients $n=116$ (for genotype frequency see article).

consistently reported in the following studies including healthy as well as diseased populations: patients with primary autoimmune hypothyroidism $(10,27)$; cohorts of athyreotic differentiated thyroid carcinoma (DTC) patients on TSH suppression therapy $(28,29)$; a cohort of females only (30); middle-aged euthyroid subjects (31); non-diabetic Amish order subjects (32); young healthy blood donors (17); elderly subjects (mean age, $>70$ years) of Caucasian origin $(6,20)$; and young healthy euthyroid men (19). In one report, including patients with Graves's disease, carrier status of the 92Ala variant was associated with a decreased $T_{3} / T_{4}$ ratio and higher serum autoantibody levels (anti-TPO and anti-Tg) (33).

Butler et al. (34) reported that the homozygous status for the 92Ala allele was associated with a decreased TSHstimulated release of $T_{3}$ from the thyroid in healthy subjects, indicative of a lower intrathyroidal conversion of $\mathrm{T}_{4}$ to $\mathrm{T}_{3}$. Supportive of this hypothesis are the observations of Torlontano et al. reporting a need for higher levothyroxine doses to suppress TSH levels in athyreotic DTC patients carrying the 92Ala allele. However, there was no difference in $\mathrm{T}_{4}$ levels between the genotype groups and this would have been expected if higher levels of $\mathrm{T}_{4}$ were needed to suppress the TSH. In addition, an impact of $\mathrm{D} 2$ variants on $\mathrm{T}_{4}$ dose could not be replicated in other cohorts on $\mathrm{T}_{4}$ replacement for primary hypothyroidism (28, $35)$. Interestingly, the D2-92Ala allele was associated with an increased risk for Graves' disease in a Russian population (36). On the other hand, in a Russian population the 92Ala variant was suggested to be protective regarding risk for Graves' disease development, severity of disease, and rate of remissions in Graves' patients (37). Guerra et al. (30), however, reported that the 92Ala variant was not associated with an increased risk of thyroid autoimmunity (defined as TPO-antibody level $>100 \mathrm{U} / \mathrm{ml}$ ).

The D2-ORF $\mathrm{a}_{\mathrm{a}}$-Gly3Asp polymorphism was associated with lower $\mathrm{fT}_{4}, \mathrm{~T}_{4}$, and $\mathrm{rT}_{3}$ serum concentrations and higher $\mathrm{T}_{3} / \mathrm{rT}_{3}$ and $\mathrm{T}_{3} / \mathrm{T}_{4}$ ratio in healthy blood 
donors (6), but not in two populations of healthy elderly men $(6,20)$. It was hypothesized that these conflicting results could be explained by an aging-related decrease in muscle mass, a major depot of D2 expression, which could lead to a decreased impact of potential functional activity of D2 on serum thyroid hormone parameters. Hoftijzer et al. (15) reported that the carriers of the D2-ORF -3 Asp variant had a lower feedback of $\mathrm{fT}_{4}$ on pituitary TSH secretion, suggesting that this polymorphism was associated with an altered setpoint of the pituitarythyroid axis. Peltsverger et al. (38) reported that the $\mathrm{D} 2-\mathrm{ORF}_{\mathrm{a}}-3$ Asp variant might confer an altered pattern of thyroid hormone secretion by showing that acute TRH-induced TSH stimulation led to a blunted $\mathrm{fT}_{4}$ secretion in carriers of the 3Asp allele, consistent with an increased activity of the D2 enzyme.

D3 polymorphisms $~$ D3 polymorphisms have not been associated with TSH or iodothyronine levels in any study evaluating the impact of D3 variants on serum thyroid hormone parameters $(10,17,21)$.

\section{GH-IGF1 axis and body composition}

Thyroid function is considered to affect the growth hormone (GH)-insulin-like growth factor (IGF1) axis, with hypothyroidism and hyperthyroidism associated with lower and normal or higher IGF1 levels respectively (24).

A haplotype containing the minor allele of the D1C785T variant and the major allele of the D1-A1814G variant (both alleles with potential decreased D1 activity) was associated with higher free IGF1 levels and higher IGF1related endpoints (such as muscle mass and muscle strength) in two populations comprising younger (mean age, 46 years) and older (mean age, 71 years) patients respectively (24). Roef et al. (19) investigated the contribution of D1 (D1-C785T and D1-rs2235544) and D2 polymorphisms (D2-Thr92Ala) on variation in body composition in a group of healthy young euthyroid men $(n=677)$ and found that minor allele carriers of the D1-C785T polymorphism had significantly higher body height and higher values of other anthropometric variables (armspan, calf height, sitting, and sternum height). Another study reported that homozygous female carriers of the Thr92Ala minor allele had significantly shorter stature (mean, $162 \mathrm{~cm}$ ) compared with subjects with other D2-Thr92Ala genotype status (mean, $166 \mathrm{~cm}, P=0.001$ ) (39). These findings might point to a potential role of deiodinase genes in determination of body height.

\section{Cognitive function and affective disorders}

Evidence suggests that thyroid hormones affect neurotransmitter activity, such as the serotonergic neurotransmission (40). The brain serotonin system is considered to be frequently involved in the pathogenesis of affective disorders and psychotropics are believed to exert their effects upon this system. Some studies in humans showed that thyroid hormone abnormalities, i.e. hypothyroidism, may be linked to reduced 5-HT (serotonin) responsiveness (40). As deiodinase activity is important for local $T_{3}$ availability in the brain and thyroid hormone status has been associated with cognitive functioning and emotional well-being $(2,41)$, it has been speculated that deiodinase polymorphisms could affect neuropsychological parameters.

Based on the notion that thyroid hormone abnormalities are associated with cognitive impairment and dementia (42), de Jong et al. (20) evaluated whether D1 and D2 polymorphisms were related to early magnetic resonance markers of Alzheimer's disease in elderly patients, for which no relationship was found.

Panicker et al. (43) demonstrated in a large cohort of patients on thyroid hormone replacement therapy that the D2-Thr92Ala variant was associated with worse baseline psychological well-being in patients on $\mathrm{T}_{4}$ replacement therapy and improved response to combined $\mathrm{T}_{4}-\mathrm{T}_{3}$ therapy. No impact of D1 or D3 polymorphisms on study outcomes was found. Confirmation of these findings in other cohorts is warranted. In a relatively small population of patients with primary autoimmune hypothyroidism $(n=141)$, D2 variants (D2-ORF ${ }_{\mathrm{a}}$-Gly3Asp and D2-Thr92Ala) have shown no association with well-being, neurocognitive function, or preference for combined $\mathrm{T}_{4}-\mathrm{T}_{3}$ therapy (27).

The influence of deiodinase polymorphisms on the development, severity, and treatment response of psychiatric disorders has not been investigated extensively. The D1-C785T polymorphism was associated with lifetime major depression in white female subjects from high-risk cohorts (22).

The hypothesis was postulated that patients with a genetically determined decreased conversion of $T_{4}$ to $T_{3}$ might benefit from the additive effect of $\mathrm{T}_{3}$ to antidepressants. Cooper-Kazaz et al. (44) reported that in a population of patients diagnosed with major depression, DI-785T carriers showed better treatment response to combined antidepressant sertraline $/ \mathrm{T}_{3}$ therapy compared with non-carriers on combined treatment. Other D1 and D2 polymorphisms (D1-A1814G, D2-ORF ${ }_{\mathrm{a}}$-Gly3Asp, and D2-Thr92Ala) did not show a relationship with 
therapeutic response in this study. Brouwer et al. (45) reported that the Thr92Ala polymorphism was not associated with response rate to antidepressant therapy with paroxetine in 96 patients treated for major depression.

In the Chinese Han population, He et al. (46) found that the D2-ORF - -Gly3Asp variant and D2-92Ala variant were linked to higher risk for bipolar mood disorder.

Recently, Colak et al. (47) have reported an association between susceptibility for schizophrenia and the D2-Thr92Ala polymorphism.

\section{Bone metabolism}

Thyroid hormones are considered to be key elements in the regulation of bone matrix synthesis (48). $\mathrm{T}_{3}$ regulates cell differentiation, bone matrix synthesis, and degradation in osteoblasts. D2 activity in these cells fulfills a vital role in the maintenance of optimal bone mineralization and strength. Bone derived from D2-knockout mice showed reduced toughness, was brittle, and had increased vulnerability to fracture, emphasizing that D2 expression is an important prerequisite for optimal bone remodeling (49). In human adults, hypothyroidism as well as hyperthyroidism is associated with an increased risk of bone fractures (50). Variation in deiodinases has been described as a potential genetic determinant of bone pathology. Two studies investigated the effect of deiodinase polymorphisms on bone-related parameters. The D2Thr92Ala polymorphism was associated with a decreased femoral neck and total hip bone mineral density and several markers of bone turnover in 154 athyreotic patients treated for DTC (51), indicating a role for D2 in regulation of bone formation. However, in a study of 641 young (25-45 years) healthy men, no effect of D1 (D1-rs22335544; D1-C785T) or D2 variants (D2-Thr92Ala) on bone mass could be found (52).

\section{Risk for osteoarthritis}

$\mathrm{T}_{3}$ is considered an important regulator of chondrocyte cell growth and differentiation in the endochondral growth plate (53). Variation in local $\mathrm{T}_{3}$ bioavailability, for example, caused by certain genetic deiodinase profiles might affect cartilage homeostasis in health and disease. The D2Thr92Ala polymorphism was related to higher risk for generalized osteoarthritis and further study in three large cohorts showed that a haplotype including the minor allele of D2-Thr92Ala and the major allele of the D2-ORF $\mathrm{a}^{-}$ Gly3Asp polymorphism was similarly associated with osteoarthritis (39). In contrast, a D3 polymorphism (D3-rs945006) was associated with a decreased risk for osteoarthritis, suggestive of a protective effect of this genetic variant (18). These findings generated the hypothesis that local $\mathrm{T}_{3}$ availability, regulated by the opposite functions of D2 and D3, may be an important determinant of susceptibility to symptomatic osteoarthritis development. Bos et al. (54) demonstrated that D2 was upregulated in osteoarthritis-affected joints and that an allelic imbalance (difference in expression of alleles) in patients might explain the positive association between the D2-92Ala variant and osteoarthritis. Waarsing et al. (55) postulated that deiodinase variants might increase vulnerability of cartilage in patients with a predispository non-optimal bone shape and showed a higher risk for osteoarthritis in carriers of the D2-ORF $F_{\mathrm{a}}$-Gly3Asp polymorphism. The exact role of deiodinase polymorphism in the genesis or progression of osteoarthritis has yet to be disentangled.

\section{Lipoprotein metabolism}

$\mathrm{T}_{3}$ regulates the expression of genes coding for proteins involved in energy utilization, lipolysis, and lipogenesis (56). Furthermore, $\mathrm{T}_{3}$ has a positive impact on upregulation of the LDL-receptor and thereby on cholesterol uptake and serum levels of cholesterol (57). Deiodinase polymorphisms may affect intracellular thyroid hormone concentration and thereby lipoprotein metabolism. The effect of the Thr92Ala polymorphism on serum lipid parameters was evaluated in various diabetic and non-diabetic cohorts $(5,32,38,58,59$, $60,61)$. No associations between HDL, LDL, total cholesterol, or triglyceride levels and genotype status were found in any of the reports studying this relationship.

\section{BMI and obesity}

$\mathrm{T}_{3}$ is considered to be a key modulator of energy expenditure and metabolic rate (62). Under certain circumstances, D2 knockout mice show an increased risk of obesity (62). In humans, subtle changes in deiodinase enzyme activity might affect energy metabolism and as such BMI or risk for obesity.

No effect of D1 polymorphisms on BMI was found in a cohort of healthy elderly men $(n=350)$ (24). The isolated effect of the D2-Thr92Ala polymorphism demonstrated no significant effect on BMI in a variety of studies in which this potential association was investigated $(5,28,29,32,34,60$, $61,63)$. In 960 non-diabetic Caucasians, carriers of both a variant (Trp64Arg) located in the $\beta 3$-adrenergic receptor (ADRB3) and the minor allele of the D2-Thr92Ala variant 
displayed an increased BMI (4). Albeit, these findings were not replicated in an other two cohorts including healthy Danish subjects and Pima Indians respectively $(61,64)$. In 139 patients with primary autoimmune hypothyroidism, carriers of the D2-92Ala allele had significantly higher BMI values (27). The D2-rs7140952 polymorphism was significantly associated with central obesity in a population with primary hypothyroidism(35).

\section{Blood pressure and hypertension}

The vasodilatory effect of $T_{3}$ and the expression and regulatory function of $\mathrm{D} 2$ in vascular smooth muscle cells hint toward a potential effect of variants in deiodinases on blood pressure $(65,66)$. The impact of deiodinase polymorphisms on cardiovascular parameters has primarily been restricted to the outcome blood pressure and demonstrates equivocal results. The D2-Thr92Ala polymorphism was associated with higher risk for arterial hypertension in 372 euthyroid subjects not on thyroid hormone replacement therapy (31). The only other positive association between this variant and blood pressure was reported by Fiorito et al. (60). Patients who are carriers of both the minor variant of D2-Thr92Ala and PPAR $\gamma 2-$ Pro12Ala polymorphism had significantly higher diastolic and systolic blood pressures. Other studies detected opposite effects. The D2-Thr92Ala polymorphism had no impact on blood pressure or risk for arterial hypertension in the two studies including only DM2 patients as well as a large unselected community-based cohort $(58,67,68)$. Similarly, van der Deure et al. (69) assessed the relationship between the Thr92Ala polymorphism and blood pressure or hypertension in two large cohorts of elderly subjects and found no consistent significant associations. The 92Ala allele may confer a decreased risk for thyrotoxicosis-related cardiomyopathy (i.e. left ventricle hypertrophy) in patients with Graves' disease, of which the authors proposed a potential protective effect of this genetic variant against hyperthyroidism-induced changes in heart tissue (33). Recently, Al-azzam et al. (35) has detected an association between the D2-rs7140952 polymorphism with diastolic and systolic blood pressure in patients on thyroid hormone replacement therapy.

\section{Insulin resistance and DM2}

Thyroid hormones have been associated with glucose homeostasis and insulin sensitivity in numerous experimental and epidemiological studies (70). Therefore, certain deiodinase profiles affecting peripheral or local thyroid hormone concentrations may be associated with the risk of insulin resistance or contribute to the development of DM2.

Research particularly focused on the role of the D2Thr92Ala polymorphism and was done in mixed-cohorts including both diabetic and non-diabetes cohorts $(n=5)$ : studies including only DM2 patients $(n=2)$ and studies including only non-diabetic subjects $(n=3)$. In the genetic association studies $(n=5)$, the relationship between D2Thr92Ala genotype status and risk for DM2 was examined. Three independent case-control studies revealed no significant association between the D2-Thr92Ala variant and risk for DM2 $(32,61,63)$. However, Dora et al. (58) performed a case-control study and a meta-analysis of the previously published studies and concluded that homozygous carriers had a higher risk for DM2 and the meta-analysis supported these findings by showing that carriers of the 92Ala allele had increased risk for DM2. The latest study on this subject from Nair et al. (64) showed that in a large cohort of Pima Indians no clear impact of D2 variants (including Thr92Ala) on insulin resistance or DM2 risk could be detected.

In two studies including only DM2 patients, a greater insulin resistance (reflected by higher fasting insulin and HOMA-IR) was reported in homozygous carriers of the D292Ala allele $(5,59)$. Dora et al. (58) replicated these results in a subset of their case-control study, including DM2 patients of European descent.

In non-diabetic cohorts, research on the relationship between deiodinase polymorphisms and measures of insulin resistance (i.e. HOMA-IR) yielded several nonsignificant reports $(31,32,60,61,64)$. Of note, a small number of DM2 patients (4.2\%) were included in the study of Grarup et al. (61). In one study, a subanalysis including a population of non-diabetic women who underwent euglycemic-hyperinsulinemic clamps to diagnose insulin resistance, a consistent strong relationship between the Thr92Ala polymorphism and lower glucose disposal rate was found, supportive of an increased risk for insulin resistance (4). Al-azzam et al. (35) found no association between diabetes and various D2 polymorphisms in a population of patients with primary hypothyroidism.

Interaction with other polymorphisms $>$ Estivalet $e t$ al. (59) reported that carriers of both the PPAR $\gamma 2-P r o 12 A l a$ and D2-Thr92Ala polymorphisms had a significantly higher insulin resistance (as measured by HOMA-IR) in DM2 patients. These findings could not be replicated by Fiorito et al. (60), reflected by a non-significant impact of combined carrier status for these polymorphisms on insulin resistance (HOMA-IR) in a cohort of non-diabetic subjects. 


\section{Gynecological parameters}

Preeclampsia tends to be accompanied by lower $\mathrm{T}_{3}$ serum levels and evidence suggests hypothyroidism could be a risk factor for this clinical entity $(71,72,73,74)$. In a preliminary report by Procopciuc et al. (23), the D1-C785T polymorphism (previously linked to decreased conversion of $\mathrm{T}_{4}$ to $\mathrm{T}_{3}$ ) was associated with degree of severity of preeclampsia, and severe preeclamptic women carrying the D1-785T variant delivered neonates with significantly lower birth weight at a significantly lower gestational age. The exact relationship is far from clear and research in larger cohorts is warranted.

\section{Sepsis and sepsis-related study endpoints (acute lung injury)}

In two preclinical mouse models, induction of acute lung injury led to upregulation of D2 gene and D2 protein. Furthermore, a significant positive relationship between D2 expression and extent of lung injury was found (75). The interaction between thyroid hormone metabolism and inflammatory response is complex and far from elucidated. Genetic D2 variants might affect inflammatory response, by affecting D2 gene and protein levels. This hypothesis was strengthened by the observed increased magnitude of lung injury in a state of reduced D2 gene and protein in mice (75). In the same study, the D2-92Ala variant was associated with a reduced susceptibility for severe sepsis and sepsis-related acute lung injury in critically ill patients of European descent, but not in patients of African origin (75). These findings may support the role of D2 in prevention of local thyroid hormone disruption in lung and other bodily tissues under inflammatory and mechanical stressors.

\section{lodine and selenium deficiency and effect of polymorphisms on disease}

Vulnerability to the potential clinical effects of polymorphisms may partly be dependent on deficiencies in chemical elements involved in proper functioning of pituitary-thyroid axis. Based on the notion that sufficient iodine availability is of vital importance in local $\mathrm{T}_{3}$ regulation for normal brain development during the fetal and early postnatal period, researchers sought to evaluate whether risk for mental retardation in iodinedeficient areas could be dependent on variation in deiodinases. Guo et al. (76) found a significant positive association between two D2 polymorphisms (rs225010 and r2225012) and risk for mental retardation in children in an iodine-deficient area of China. Recently, Zhang et al. (77) have confirmed that children's susceptibility to mental retardation might be related to certain D2 polymorphisms (rs225015, rs2267872, rs1388378). Of note, the D2-Thr92Ala polymorphism (rs225014) was not associated with mental retardation in either study.

Deiodinases are selenoproteins and selenium is an important building block for their proper activity (78). Selenium deficiency has the potential to impair expression of D2 activity $(79,80)$. Vulnerability to the clinical effects of selenium deficiency might be dependent on genetic thyroid hormone profile. Gentschew et al. (81) reported that the significantly lower selenium levels detected in patients with Crohn's disease may contribute to its development and found that variation in D1 and D2 was significantly associated with modified selenium serum levels. Albeit, after multiple testing, no significant associations remained. Xiong et al. (82) evaluated whether the D2-Thr92Ala variant could influence the risk of Kashin-Beck disease, a chronic endemic osteochondropathy found in selenium-deficient areas of China, south-east Siberia, and North-Korea, and found no significant association of this genetic variant with the disease. The interaction between selenium or iodine deficiency, genetic variation in deiodinases and health effects is a scarcely investigated domain and may be a worthwhile field of future research.

\section{Points to consider in the interpretation of studies on genetic polymorphisms}

Thyroid hormones exert a myriad of functions in a variety of tissues. Since deiodinases are key regulators of peripheral and local thyroid hormone metabolism, research on the effect of deiodinase gene variation has grown over the last few years and could be considered a valuable tool to investigate the effect of thyroid hormone regulation on the end-organ level and thus on the expression of clinical phenotypes. Although many studies showed evidence of deiodinase polymorphisms on thyroid hormone-related endpoints, clinical implications of deiodinase variants are far from clarified.

One of the major impediments to provide general statements about the impact of deiodinase polymorphisms on clinical outcomes is the diversity in study cohorts (83). The action of deiodinase variations on clinical endpoints may simply be non-uniform in different populations for several reasons:

i) for instance, aging has been suggested as a factor that could explain the different impact of D1 and D2 deiodinase variants found in younger and older 
European cohorts (7). The contribution of D2 to serum $\mathrm{T}_{3}$ production may be lower in elderly compared with younger cohorts, caused by a decrease in skeletal muscle mass, an important source of D2, during aging $(3,7)$.

ii) In the CNS, upregulation of D2 and downregulation of D3 are physiological components of the response to iodine deficiency (84). Iodine deficiency might expose otherwise non-identified effects of genetic deiodinase variants. Studies were performed in different geographical areas in which dietary factors such as iodine status may vary.

iii) Study populations were from diverse geographical background (i.e. the old Amish order, South-American, Danish, and Mixed European) with different genetic make-up and as such study results on the same subject matter may not be plainly comparable.

iv) Deiodinase levels may vary dependent on intactness of the pituitary-thyroid axis. Synthetic thyroid hormone analogs such as $\mathrm{T}_{4}$ could be potent inhibitors of deiodinases (1). Long-term TSH suppression therapy could lead to significant changes in thyroid hormone metabolism, best explained by downregulation of D1 and D2 activity and upregulation of D3 (85). Thyroid function abnormalities (hypothyroidism and hyperthyroidism) are associated with changes in deiodinase levels (1).

v) It cannot be ignored that the functional characterization of deiodinase variants is far from complete $(8,11,14,17$, 67). Although significant associations are rather robust it could not be excluded that genetic markers considered significant may be associated with other deiodinase polymorphisms which are in linkage disequilibrium with these variants.

Besides these true underlying differences, variation in sample size (decreased power to detect significant difference) might contribute to different effects of the polymorphisms in different studies. Subtle effects of deiodinase variants on thyroid hormone-related parameters might be difficult to detect in relatively small sample sizes (decreased power). Significant relationships detected in small studies should be replicated in larger patient cohorts to decrease the risk of adopting potential false-positive assumptions. The risk of publication bias in genetic association studies could also not be excluded.

\section{Conclusions and role of deiodinase polymorphisms in the clinical setting}

Although the effect of genetic variation on inter-individual TSH and thyroid hormone levels is relatively large (65\%), evidence suggests that genetic deiodinase profiles only explain a small proportion of inter-individual variation in serum thyroid hormone levels. These observations are in line with the general notion that circulating thyroid hormone levels and related phenotypes are under control of a complex interplay between multiple genes and environmental factors. A multitude of studies determined a promising role of deiodinase variants on clinical outcomes. D1 polymorphisms particularly showed a strong relationship with serum thyroid hormone parameters (D1-C785T and D1rs2234455), IGF1 production (D1-C785T) and risk for major depression (D1-C785T) and D2 variants with serum thyroid hormone parameters (D2-ORF $\mathrm{a}-\mathrm{Gly} 3 \mathrm{Asp})$, insulin resistance parameters (D2Thr92Ala), bipolar mood disorder (D2-Thr92Ala), psychological well-being (D2Thr92Ala), mental retardation, hypertension (D2-Thr92Ala), and risk for osteoarthritis (D2-Thr92Ala). D3 polymorphisms showed no relationship with inter-individual variation in serum thyroid hormone parameters. A D3 polymorphism (D3-rs945006) was associated with risk for osteoarthritis.

Evidence suggests no major impact of deiodinase variants on risk for obesity or lipoprotein metabolism. Potential associations between deiodinase polymorphism status and risk for thyroid disease, sepsis, and pregnancy outcomes are noteworthy, but need further confirmation. In summary, this systematic review showed the variety in available evidence on the effect of deiodinase variants on clinical endpoints. The significance of deiodinase polymorphisms for clinical practice seems to be limited from the studies conducted so far, but future studies are needed to unravel the exact role of deiodinase polymorphisms as contributors or therapeutic targets in the clinical setting.

\section{Supplementary data}

This is linked to the online version of the paper at http://dx.doi.org/10.1530/ EJE-14-0302

Declaration of interest

The authors declare that there is no conflict of interest that could be perceived as prejudicing the impartiality of the review.

\section{Funding}

This review did not receive any specific grant from any funding agency in the public, commercial or not-for-profit sector.

\section{References}

1 Kohrle J. Local activation and inactivation of thyroid hormones: the deiodinase family. Molecular and Cellular Endocrinology 1999151 103-119. (doi:10.1016/S0303-7207(99)00040-4) 
2 Bianco AC, Salvatore D, Gereben B, Berry MJ \& Larsen PR. Biochemistry, cellular and molecular biology, and physiological roles of the iodothyronine selenodeiodinases. Endocrine Reviews 200223 38-89. (doi:10.1210/edrv.23.1.0455)

3 Maia AL, Kim BW, Huang SA, Harney JW \& Larsen PR. Type 2 iodothyronine deiodinase is the major source of plasma $T_{3}$ in euthyroid humans. Journal of Clinical Investigation 2005115 2524-2533. (doi:10.1172/JCI25083)

4 Mentuccia D, Proietti-Pannunzi L, Tanner K, Bacci V, Pollin TI, Poehlman ET, Shuldiner AR \& Celi FS. Association between a novel variant of the human type 2 deiodinase gene Thr92Ala and insulin resistance: evidence of interaction with the Trp64Arg variant of the $\beta$-3-adrenergic receptor. Diabetes 200251 880-883. (doi:10.2337/ diabetes.51.3.880)

5 Canani LH, Capp C, Dora JM, Meyer EL, Wagner MS, Harney JW, Larsen PR, Gross JL, Bianco AC \& Maia AL. The type 2 deiodinase A/G (Thr92Ala) polymorphism is associated with decreased enzyme velocity and increased insulin resistance in patients with type 2 diabetes mellitus. Journal of Clinical Endocrinology and Metabolism 200590 3472-3478. (doi:10.1210/jc.2004-1977)

6 Peeters RP, van den Beld AW, Attalki H, Toor H, de Rijke YB, Kuiper GG, Lamberts SW, Janssen JA, Uitterlinden AG \& Visser TJ. A new polymorphism in the type II deiodinase gene is associated with circulating thyroid hormone parameters. American Journal of Physiology. Endocrinology and Metabolism 2005289 E75-E81. (doi:10.1152/ajpendo. 00571.2004)

7 Peeters RP, van der Deure WM \& Visser TJ. Genetic variation in thyroid hormone pathway genes; polymorphisms in the TSH receptor and the iodothyronine deiodinases. European Journal of Endocrinology 2006155 655-662. (doi:10.1530/eje.1.02279)

8 Coppotelli G, Summers A, Chidakel A, Ross JM \& Celi FS. Functional characterization of the $258 \mathrm{~A} / \mathrm{G}$ (D2-ORFa-Gly3Asp) human type-2 deiodinase polymorphism: a naturally occurring variant increases the enzymatic activity by removing a putative repressor site in the $5^{\prime}$ UTR of the gene. Thyroid $2006 \mathbf{1 6} 625-632$. (doi:10.1089/thy.2006.16.625)

9 Maia AL, Goemann IM, Meyer EL \& Wajner SM. Deiodinases: the balance of thyroid hormone: type 1 iodothyronine deiodinase in human physiology and disease. Journal of Endocrinology 2011209 283-297. (doi:10.1530/JOE-10-0481)

10 Panicker V, Cluett C, Shields B, Murray A, Parnell KS, Perry JR, Weedon MN, Singleton A, Hernandez D, Evans J et al. A common variation in deiodinase 1 gene DIO1 is associated with the relative levels of free thyroxine and triiodothyronine. Journal of Clinical Endocrinology and Metabolism 200893 3075-3081. (doi:10.1210/jc.2008-0397)

11 van der Deure WM, Hansen PS, Peeters RP, Uitterlinden AG, Fenger M, Kyvik KO, Hegedus L \& Visser TJ. The effect of genetic variation in the type 1 deiodinase gene on the interindividual variation in serum thyroid hormone levels: an investigation in healthy Danish twins. Clinical Endocrinology 200970 954-960. (doi:10.1111/j.1365-2265. 2008.03420.x)

12 Dixon AL, Liang L, Moffatt MF, Chen W, Heath S, Wong KC, Taylor J, Burnett E, Gut I, Farrall $\mathrm{M}$ et al. A genome-wide association study of global gene expression. Nature Genetics 200739 1202-1207. (doi:10.1038/ng2109)

13 Celi FS, Canettieri G, Mentuccia D, Proietti-Pannunzi L, Fumarola A, Sibilla R, Predazzi V, Ferraro M, Andreoli M \& Centanni M. Structural organization and chromosomal localization of the human type II deiodinase gene. European Journal of Endocrinology 2000143 267-271. (doi:10.1530/eje.0.1430267)

14 Gereben B, Kollar A, Harney JW \& Larsen PR. The mRNA structure has potent regulatory effects on type 2 iodothyronine deiodinase expression. Molecular Endocrinology 200216 1667-1679. (doi:10.1210/ mend.16.7.0879)

15 Hoftijzer HC, Heemstra KA, Visser TJ, le Cessie S, Peeters RP, Corssmit EP \& Smit JW. The type 2 deiodinase ORFa-Gly3Asp polymorphism (rs12885300) influences the set point of the hypothalamus-pituitary-thyroid axis in patients treated for differentiated thyroid carcinoma. Journal of Clinical Endocrinology and Metabolism 201196 E1527-E1533. (doi:10.1210/jc.2011-0235)

16 Dentice M, Bandyopadhyay A, Gereben B, Callebaut I, Christoffolete MA, Kim BW, Nissim S, Mornon JP, Zavacki AM, Zeold A et al. The Hedgehog-inducible ubiquitin ligase subunit WSB-1 modulates thyroid hormone activation and PTHrP secretion in the developing growth plate. Nature Cell Biology 20057 698-705. (doi:10.1038/ncb1272)

17 Peeters RP, van Toor H, Klootwijk W, de Rijke YB, Kuiper GG, Uitterlinden AG \& Visser TJ. Polymorphisms in thyroid hormone pathway genes are associated with plasma TSH and iodothyronine levels in healthy subjects. Journal of Clinical Endocrinology and Metabolism 200388 2880-2888. (doi:10.1210/jc.2002021592)

18 Meulenbelt I, Bos SD, Chapman K, van der Breggen R, HouwingDuistermaat JJ, Kremer D, Kloppenburg M, Carr A, Tsezou A, Gonzalez A et al. Meta-analyses of genes modulating intracellular $\mathrm{T}_{3}$ bio-availability reveal a possible role for the DIO3 gene in osteoarthritis susceptibility. Annals of the Rheumatic Diseases 201170 164-167. (doi:10.1136/ard.2010.133660)

19 Roef G, Guillemaere S, De NH, Vandewalle S, Taes YE \& Kaufman J-M. Iodothyronine deiodinase 1 polymorphisms are associated with body height. Endocrine Reviews 200332 (03_MeetingAbstracts) P3-587 (Conference).

20 de Jong FJ, Peeters RP, den Heijer T, van der Deure WM, Hofman A, Uitterlinden AG, Visser TJ \& Breteler MM. The association of polymorphisms in the type 1 and 2 deiodinase genes with circulating thyroid hormone parameters and atrophy of the medial temporal lobe. Journal of Clinical Endocrinology and Metabolism 200792 636-640. (doi:10.1210/jc.2006-1331)

21 Medici M, Van Der Deure W, Van MJ, Hansen P, Verbiest M, Iachine I, Hegedus L, Uitterlinden AG, Visser TJ \& Peeters RP. A large scale association analysis of 68 thyroid hormone pathway genes with TSH and $\mathrm{FT}_{4}$. European Journal of Endocrinology 2011164 781-788. (doi:10.1530/EJE-10-1130)

22 Philibert RA, Beach SR, Gunter TD, Todorov AA, Brody GH, Vijayendran M, Elliott L, Hollenbeck N, Russell D \& Cutrona C. The relationship of deiodinase 1 genotype and thyroid function to lifetime history of major depression in three independent populations. American Journal of Medical Genetics. Part B, Neuropsychiatric Genetics 2011 156B 593-599. (doi:10.1002/ajmg.b.31200)

23 Procopciuc LM, Hazi GM, Caracostea G, Nemeti G, Olteanu I, Dragatoiu GH \& Stamatian F. The effect of the D1-C785T polymorphism in the type 1 iodothyronine deiodinase gene on the circulating thyroid hormone levels in Romanian women with preeclampsia. Association with the degree of severity and pregnancy outcome of preeclampsia. Gynecological Endocrinology 201228 386-390. (doi:10.3109/09513590.2011.633655)

24 Peeters RP, van den Beld AW, van Toor H, Uitterlinden AG, Janssen JA, Lamberts SW \& Visser TJ. A polymorphism in type I deiodinase is associated with circulating free insulin-like growth factor I levels and body composition in humans. Journal of Clinical Endocrinology and Metabolism 200590 256-263. (doi:10.1210/jc.2004-1301)

25 Taylor P, Panicker V, Iqbal A, Timpson N, Walsh J \& Dayan C. The effect of genetic variation in PDE8B and DIO1 on thyroid hormone levels. Endocrine Abstracts 201021 OC5.8.

26 Porcu E, Medici M, Pistis G, Volpato CB, Wilson SG, Cappola AR, Bos SD, Deelen J, den Heijer M, Freathy RM et al. A meta-analysis of thyroid-related traits reveals novel loci and gender-specific differences in the regulation of thyroid function. PLoS Genetics 20139 e1003266. (doi:10.1371/journal.pgen.1003266)

27 Appelhof BC, Peeters RP, Wiersinga WM, Visser TJ, Wekking EM, Huyser J, Schene AH, Tijssen JG, Hoogendijk WJ \& Fliers E. Polymorphisms in type 2 deiodinase are not associated with well-being, neurocognitive functioning, and preference for combined thyroxine/ 
3,5,3'-triiodothyronine therapy. Journal of Clinical Endocrinology and Metabolism 200590 6296-6299. (doi:10.1210/jc.2005-0451)

28 Heemstra KA, Hoftijzer HC, van der Deure WM, Peeters RP, Fliers E, Appelhof BC, Wiersinga WM, Corssmit EP, Visser TJ \& Smit JW. Thr92Ala polymorphism in the type 2 deiodinase is not associated with $\mathrm{T}_{4}$ dose in athyroid patients or patients with Hashimoto thyroiditis. Clinical Endocrinology 200971 279-283. (doi:10.1111/j.1365-2265. 2008.03474.x)

29 Torlontano M, Durante C, Torrente I, Crocetti U, Augello G, Ronga G, Montesano T, Travascio L, Verrienti A, Bruno R et al. Type 2 deiodinase polymorphism (threonine 92 alanine) predicts L-thyroxine dose to achieve target thyrotropin levels in thyroidectomized patients. Journal of Clinical Endocrinology and Metabolism 200893 910-913. (doi:10.1210/jc.2007-1067)

30 Guerra A, Sapio MR, Carrano M, Di Stasi V, Volpe A, Murino A, Izzo G \& Vitale M. Prevalence of Dio2 T92A polymorphism and its association with thyroid autoimmunity. Journal of Endocrinological Investigation 201236 303-306. (doi:10.3275/8618)

31 Gumieniak O, Perlstein TS, Williams JS, Hopkins PN, Brown NJ, Raby BA \& Williams GH. Ala92 type 2 deiodinase allele increases risk for the development of hypertension. Hypertension 200749 461-466. (doi:10.1161/01.HYP.0000256295.72185.fd)

32 Mentuccia D, Thomas MJ, Coppotelli G, Reinhart LJ, Mitchell BD, Shuldiner AR \& Celi FS. The Thr92Ala deiodinase type 2 (DIO2) variant is not associated with type 2 diabetes or indices of insulin resistance in the old order of Amish. Thyroid 200515 1223-1227. (doi:10.1089/thy. 2005.15.1223)

33 Grineva E, Babenko A, Vahrameeva N, Bogdanova M, Kostareva A, Popcova D \& Larionova V. Type 2 deiodinase Thr92Ala polymorphism impact on clinical course and myocardial remodeling in patients with Graves' disease. Cell Cycle 20098 2565-2569. (doi:10.4161/cc.8.16.9250)

34 Butler PW, Smith SM, Linderman JD, Brychta RJ, Alberobello AT, Dubaz OM, Luzon JA, Skarulis MC, Cochran CS, Wesley RA et al. The Thr92Ala $5^{\prime}$ type 2 deiodinase gene polymorphism is associated with a delayed triiodothyronine secretion in response to the thyrotropinreleasing hormone-stimulation test: a pharmacogenomic study. Thyroid 201020 1407-1412. (doi:10.1089/thy.2010.0244)

35 Al-azzam SI, Alkhateeb AM, Al-Azzeh O, Alzoubi KH \& Khabour OF. The role of type II deiodinase polymorphisms in clinical management of hypothyroid patients treated with levothyroxine. Experimental and Clinical Endocrinology \& Diabetes 2013121 300-305. (doi:10.1055/ s-0032-1331695)

36 Chistiakov DA, Savost'anov KV \& Turakulov RI. Screening of SNPs at 18 positional candidate genes, located within the GD-1 locus on chromosome 14q23-q32, for susceptibility to Graves' disease: a TDT study. Molecular Genetics and Metabolism 200483 264-270. (doi:10.1016/j.ymgme.2004.07.011)

37 Babenko A, Daria P, Olga F, Vladislav S, Anna K \& Elena G. Thr92Ala polymorphism of human type 2 deiodinase gene (hD2) affects the development of Graves' disease, treatment efficiency, and rate of remission. Clinical \& Developmental Immunology, 2012 1-5. Article ID 340542. (doi:10.1155/2012/340542)

38 Peltsverger MY, Butler PW, Alberobello AT, Smith S, Guevara Y, Dubaz OM, Luzon JA, Linderman J \& Celi FS. The $-258 \mathrm{~A} / \mathrm{G}$ (SNP rs12885300) polymorphism of the human type 2 deiodinase gene is associated with a shift in the pattern of secretion of thyroid hormones following a TRH-induced acute rise in TSH. European Journal of Endocrinology 2012166 839-845. (doi:10.1530/EJE-11-1073)

39 Meulenbelt I, Min JL, Bos S, Riyazi N, Houwing-Duistermaat JJ, van der Wijk HJ, Kroon HM, Nakajima M, Ikegawa S, Uitterlinden AG et al. Identification of DIO2 as a new susceptibility locus for symptomatic osteoarthritis. Human Molecular Genetics 200817 1867-1875. (doi:10.1093/hmg/ddn082)

40 Bauer M, Heinz A \& Whybrow PC. Thyroid hormones, serotonin and mood: of synergy and significance in the adult brain. Molecular Psychiatry 20027 140-156. (doi:10.1038/sj.mp.4000963)
41 Davis CD, Tsuji PA \& Milner JA. Selenoproteins and cancer prevention. Annual Review of Nutrition 201232 73-95. (doi:10.1146/annurevnutr-071811-150740)

42 Dugbartey AT. Neurocognitive aspects of hypothyroidism. Archives of Internal Medicine 1998158 1413-1418. (doi:10.1001/archinte.158.13.1413)

43 Panicker V, Saravanan P, Vaidya B, Evans J, Hattersley A, Frayling T \& Dayan C. Common variation in the $\mathrm{DIO} 2$ gene predicts baseline psychological well-being and response to combination $\mathrm{T}_{4} / \mathrm{T}_{3}$ therapy in patients on thyroid hormone replacement. Journal of Clinical Endocrinology and Metabolism 200994 1623-1629 (Conference 357). (doi:10.1210/jc.2008-1301)

44 Cooper-Kazaz R, van der Deure WM, Medici M, Visser TJ, Alkelai A, Glaser B, Peeters RP \& Lerer B. Preliminary evidence that a functional polymorphism in type 1 deiodinase is associated with enhanced potentiation of the antidepressant effect of sertraline by triiodothyronine. Journal of Affective Disorders 2009 116 113-116. (doi:10.1016/j.jad.2008.10.019)

45 Brouwer JP, Appelhof BC, Peeters RP, Hoogendijk WJ, Huyser J, Schene AH, Tijssen JG, Van Dyck R, Visser TJ, Wiersinga WM et al. Thyrotropin, but not a polymorphism in type II deiodinase, predicts response to paroxetine in major depression. European Journal of Endocrinology 2006154 819-825. (doi:10.1530/eje.1.02155)

46 He B, Li J, Wang G, Ju W, Lu Y, Shi Y, He L \& Zhong N. Association of genetic polymorphisms in the type II deiodinase gene with bipolar disorder in a subset of Chinese population. Progress in Neuro-Psychopharmacology \& Biological Psychiatry 200933 986-990. (doi:10.1016/j.pnpbp.2009.05.003)

47 Colak A, Akan G, Oncu F et al. 1508 Çô Association study of the dio2 gene as a susceptibility candidate for schizophrenia in the Turkish population; a case-control study. European Psychiatry 2013281. (doi:10.1016/S0924-9338(13))

48 Gogakos AI, Duncan Bassett JH \& Williams GR. Thyroid and bone. Archives of Biochemistry and Biophysics 2010503 129-136. (doi:10.1016/ j.abb.2010.06.021)

49 Bassett JH, Boyde A, Howell PG, Bassett RH, Galliford TM, Archanco M, Evans H, Lawson MA, Croucher P, St Germain DL et al. Optimal bone strength and mineralization requires the type 2 iodothyronine deiodinase in osteoblasts. PNAS 2010107 7604-7609. (doi:10.1073/ pnas.0911346107)

50 Waung JA, Bassett JH \& Williams GR. Thyroid hormone metabolism in skeletal development and adult bone maintenance. Trends in Endocrinology and Metabolism 201223 155-162. (doi:10.1016/j.tem.2011.11.002)

51 Heemstra KA, Hoftijzer H, van der Deure WM, Peeters RP, Hamdy NA, Pereira A, Corssmit EP, Romijn JA, Visser TJ \& Smit JW. The type 2 deiodinase Thr92Ala polymorphism is associated with increased bone turnover and decreased femoral neck bone mineral density. Journal of Bone and Mineral Research 201025 1385-1391. (doi:10.1002/jbmr.27)

52 Roef G, Vandewalle S, Goemaere S, Zmierczak H, Kaufman J-M \& Taes $\mathrm{Y}$. Bone mass in young men is inversely associated with free triiodothyronine, but not with polymorphisms in deiodinases. Osteoporosis International 201122 (Suppl 1) S365-S366 (Conference).

53 Robson H, Siebler T, Stevens DA, Shalet SM \& Williams GR. Thyroid hormone acts directly on growth plate chondrocytes to promote hypertrophic differentiation and inhibit clonal expansion and cell proliferation. Endocrinology 2000141 3887-3897. (doi:10.1210/endo.141.10.7733)

54 Bos SD, Bovee JV, Duijnisveld BJ, Raine EV, van Dalen WJ, Ramos YF, van der Breggen R, Nelissen RG, Slagboom PE, Loughlin J et al. Increased type II deiodinase protein in OA-affected cartilage and allelic imbalance of OA risk polymorphism rs225014 at DIO2 in human OA joint tissues. Annals of the Rheumatic Diseases 201271 1254-1258. (doi:10.1136/annrheumdis-2011-200981)

55 Waarsing JH, Kloppenburg M, Slagboom PE, Kroon HM, HouwingDuistermaat JJ, Weinans H \& Meulenbelt I. Osteoarthritis susceptibility genes influence the association between hip morphology and osteoarthritis. Arthritis and Rheumatism 201163 1349-1354. (doi:10.1002/art.30288) 
56 Oppenheimer JH, Schwartz HL, Lane JT \& Thompson MP. Functional relationship of thyroid hormone-induced lipogenesis, lipolysis, and thermogenesis in the rat. Journal of Clinical Investigation $1991 \mathbf{8 7}$ 125-132. (doi:10.1172/JCI114961)

57 Lopez D, Abisambra Socarras JF, Bedi M \& Ness GC. Activation of the hepatic LDL receptor promoter by thyroid hormone. Biochimica et Biophysica Acta 2007 1771 1216-1225. (doi:10.1016/j.bbalip.2007.05.001)

58 Dora JM, Machado WE, Rheinheimer J, Crispim D \& Maia AL. Association of the type 2 deiodinase Thr92Ala polymorphism with type 2 diabetes: case-control study and meta-analysis. European Journal of Endocrinology 2010163 427-434. (doi:10.1530/EJE-10-0419)

59 Estivalet AA, Leiria LB, Dora JM, Rheinheimer J, Boucas AP, Maia AL \& Crispim D. D2 Thr92Ala and PPAR $\gamma 2$ Pro12Ala polymorphisms interact in the modulation of insulin resistance in type 2 diabetic patients. Obesity 201119 825-832. (doi:10.1038/oby.2010.231)

60 Fiorito M, Torrente I, De Cosmo S, Guida V, Colosimo A, Prudente S, Flex E, Menghini R, Miccoli R, Penno G et al. Interaction of DIO2 T92A and PPAR $\gamma 2$ P12A polymorphisms in the modulation of metabolic syndrome. Obesity 200715 2889-2895. (doi:10.1038/oby.2007.343)

61 Grarup N, Andersen MK, Andreasen CH, Albrechtsen A, BorchJohnsen K, Jorgensen T, Auwerx J, Schmitz O, Hansen T \& Pedersen O. Studies of the common DIO2 Thr92Ala polymorphism and metabolic phenotypes in 7342 Danish white subjects. Journal of Clinical Endocrinology and Metabolism 200792 363-366. (doi:10.1210/jc.2006-1958)

62 Kim BW \& Bianco AC. For some, L-thyroxine replacement might not be enough: a genetic rationale. Journal of Clinical Endocrinology and Metabolism 200994 1521-1523. (doi:10.1210/jc.2009-0410)

63 Maia AL, Dupuis J, Manning A, Liu C, Meigs JB, Cupples LA, Larsen PR $\&$ Fox CS. The type 2 deiodinase (DIO2) A/G polymorphism is not associated with glycemic traits: the Framingham Heart Study. Thyroid 200717 199-202. (doi:10.1089/thy.2006.0298)

64 Nair S, Muller YL, Ortega E, Kobes S, Bogardus C \& Baier LJ. Association analyses of variants in the DIO2 gene with early-onset type 2 diabetes mellitus in Pima Indians. Thyroid 201222 80-87. (doi:10.1089/thy.2010.0455)

65 Kasahara T, Tsunekawa K, Seki K, Mori M \& Murakami M. Regulation of iodothyronine deiodinase and roles of thyroid hormones in human coronary artery smooth muscle cells. Atherosclerosis 2006186 207-214. (doi:10.1016/j.atherosclerosis.2005.07.018)

66 Ojamaa K, Klemperer JD \& Klein I. Acute effects of thyroid hormone on vascular smooth muscle. Thyroid 19966 505-512. (doi:10.1089/thy. 1996.6.505)

67 Canani LH, Leie MA, Machado WE, Capp C \& Maia AL. Type 2 deiodinase Thr92Ala polymorphism is not associated with arterial hypertension in type 2 diabetes mellitus patients. Hypertension 200749 e47. (doi:10.1161/HYPERTENSIONAHA.107.088278)

68 Maia AL, Hwang SJ, Levy D, Larson MG, Larsen PR \& Fox CS. Lack of association between the type 2 deiodinase $\mathrm{A} / \mathrm{G}$ polymorphism and hypertensive traits: the Framingham Heart Study. Hypertension 200851 e22-e23. (doi:10.1161/HYPERTENSIONAHA.107.109454)

69 van der Deure WM, Peeters RP, Uitterlinden AG, Hofman A, Breteler MM, Witteman J \& Visser TJ. Impact of thyroid function and polymorphisms in the type 2 deiodinase on blood pressure: the Rotterdam Study and the Rotterdam Scan Study. Clinical Endocrinology 200971 137-144. (doi:10.1111/j.1365-2265.2008.03447.x)

70 Chidakel A, Mentuccia D \& Celi FS. Peripheral metabolism of thyroid hormone and glucose homeostasis. Thyroid 200515 899-903. (doi:10.1089/thy.2005.15.899)

71 Wilson KL, Casey BM, McIntire DD, Halvorson LM \& Cunningham FG. Subclinical thyroid disease and the incidence of hypertension in pregnancy. Obstetrics and Gynecology 2012119 315-320. (doi:10.1097/ AOG.0b013e318240de6a)

72 Basbug M, Aygen E, Tayyar M, Tutus A, Kaya E \& Oktem O. Correlation between maternal thyroid function tests and endothelin in preeclampsia-eclampsia. Obstetrics and Gynecology 199994 551-555. (doi:10.1016/S0029-7844(99)00332-4)

73 Larijani B, Marsoosi V, Aghakhani S, Moradi A \& Hashemipour S. Thyroid hormone alteration in pre-eclamptic women. Gynecological Endocrinology 200418 97-100. (doi:10.1080/09513590310001652973)

74 van den Boogaard E, Vissenberg R, Land JA, van Wely M, van der Post JA, Goddijn M \& Bisschop PH. Significance of (sub)clinical thyroid dysfunction and thyroid autoimmunity before conception and in early pregnancy: a systematic review. Human Reproduction Update 201117 605-619. (doi:10.1093/humupd/dmr024)

75 Ma SF, Xie L, Pino-Yanes M, Sammani S, Wade MS, Letsiou E, Siegler J, Wang T, Infusino G, Kittles RA et al. Type 2 deiodinase and host responses of sepsis and acute lung injury. American Journal of Respiratory Cell and Molecular Biology 201145 1203-1211. (doi:10.1165/rcmb.2011-0179OC)

76 Guo TW, Zhang FC, Yang MS, Gao XC, Bian L, Duan SW, Zheng ZJ, Gao JJ, Wang H, Li RL et al. Positive association of the DIO2 (deiodinase type 2) gene with mental retardation in the iodine-deficient areas of China. Journal of Medical Genetics 200441 585-590. (doi:10.1136/jmg. 2004.019190)

77 Zhang K, Xi H, Wang X, Guo Y, Huang S, Zheng Z, Zhang F \& Gao X. A family-based association study of DIO2 and children mental retardation in the Qinba region of China. Journal of Human Genetics 201257 14-17. (doi:10.1038/jhg.2011.121)

78 Rayman MP. The importance of selenium to human health. Lancet 2000 356 233-241. (doi:10.1016/S0140-6736(00)02490-9)

79 Curcio C, Baqui MM, Salvatore D, Rihn BH, Mohr S, Harney JW, Larsen PR $\&$ Bianco AC. The human type 2 iodothyronine deiodinase is a selenoprotein highly expressed in a mesothelioma cell line. Journal of Biological Chemistry 2001276 30183-30187. (doi:10.1074/jbc.C100325200)

80 Pallud S, Lennon AM, Ramauge M, Gavaret JM, Croteau W, Pierre M, Courtin F \& St Germain DL. Expression of the type II iodothyronine deiodinase in cultured rat astrocytes is selenium-dependent. Journal of Biological Chemistry 1997 272 18104-18110. (doi:10.1074/jbc.272.29.18104)

81 Gentschew L, Bishop KS, Han DY, Morgan AR, Fraser AG, Lam WJ, Karunasinghe N, Campbell B \& Ferguson LR. Selenium, selenoprotein genes and Crohn's disease in a case-control population from Auckland, New Zealand. Nutrients 20124 1247-1259. (doi:10.3390/nu4091247)

82 Xiong YM, Mo XY, Zou XZ, Song RX, Sun WY, Lu W, Chen Q, Yu YX \& Zang WJ. Association study between polymorphisms in selenoprotein genes and susceptibility to Kashin-Beck disease. Osteoarthritis and Cartilage 201018 817-824. (doi:10.1016/j.joca.2010.02.004)

83 Dekkers OM, von EE, Algra A, Romijn JA \& Vandenbroucke JP. How to assess the external validity of therapeutic trials: a conceptual approach. International Journal of Epidemiology 201039 89-94. (doi:10.1093/ije/dyp174)

84 Peeters R, Fekete C, Goncalves C, Legradi G, Tu HM, Harney JW, Bianco AC, Lechan RM \& Larsen PR. Regional physiological adaptation of the central nervous system deiodinases to iodine deficiency. American Journal of Physiology. Endocrinology and Metabolism 2001281 E54-E61.

85 Verburg FA, Smit JW, Grelle I, Visser TJ, Peeters RP \& Reiners C. Changes within the thyroid axis after long-term TSH-suppressive levothyroxine therapy. Clinical Endocrinology 201276 577-581. (doi:10.1111/j.1365-2265.2011.04262.x)

86 Bos SD, Loughlin J, Nelissen RG, Slagboom PE \& Meulenbelt I. Functional characterization of OA risk polymorphism rs225014 at DIO2 in human OA cartilage. Osteoarthritis and Cartilage 201018 (Suppl 2) S14.
Received 14 April 2014

Revised version received 21 May 2014

Accepted 30 May 2014 